in 1908. He was the eldest of a family of five, his four sisters being quite well. The disease began on the right cheek with the formation of a "lump" which "burst" and discharged. Eventually the ulceration spread over the cheek as high as the outer canthus and lower lid and across to the middle line of the nose. It was scraped, and the boy had medicine; under this treatment the ulcer healed. Three months before admission a sore appeared upon the upper lip and gradually spread; one month before admission the lower lip began to swell and the swelling ruptured to form an ulcer which rapidly spread. (Fig. 4.)

On admission there was extensive scarring of the right cheek leading to ectropion, and the whole of the right ala nasi had been destroyed. The extent of the ulceration around the mouth is shown in the figure. Once more let me impress the point that this destruction of the upper lip had taken place in three months, and that on the lower lip in one month. There were characteristic Hutchinson teeth well seen in the figure. There was no interstitial keratitis and the hearing was normal. The abdominal organs presented no sign of disease. The bones were also unaffected. This case was also sent to the hospital with the diagnosis of lupus vulgaris.

The boy was treated by mercurial inunction, and 5.grain doses of potassium iodide. The ulcers were fomented and dressed with an ointment of peroxide of zinc. The inunction was continued for 16 days, when the gums were slightly affected. The ulcers had entirely healed in one month. The boy, I may add, gave a negative Calmette reaction to tuberculin.

CASE 4.-This is the photograph of another case of the same type. The patient was a girl, 16 years of age. She also showed the infantilism which $I$ have mentioned in the first two cases. The eruption began when she was 13 years old, on the side of the nose, and gradually spread. She had attended a throat hospital, where an operation was performed. Six weeks before her admission an ulcer developed upon the left side of the upper lip, and about the same time a swelling appeared at the outer part of the right eyebrow, and this swelling subsequently broke down into an ulcer.

On admission the whole of the ala nasi on each side and the lower part of the nose had been destroyed; and the area was covered with dirty crusts of dried pus. There were a similar ulcer covered with crust at the left side of the upper lip and a large brownish crust, from the side of which pus was exuding, at the outer side of the right eyebrow. (Fig. 5.) There was a ragged hole in the hard palate. The tonsils, uvula, and the whole of the soft palate had disappeared. The upper incisor teeth were of the Hutchinson type.

There were no visceral complications, but there was interstitial keratitis in both eyes. The hearing was not affected. Under mercurial inunction and iodides the ulceration healed completely in 21 days. The lesions were dressed with iodoform ointment. The girl has been provided with a false nose, and this has improved her appearance remarkably. This patient was also sent to the Finsen light department as a case of lupus vulgaris.

CASE 5.--The last patient I have to present is one some of you may remember as being under treatment last year. He was admitted on Sept. 24th, 1912, and illustrates the extent of the deformity seen in some of these untreated cases. The history was that when the patient was 8 years of age he had a blow on the nose, and that 12 months later a "lump" which had formed "broke," Ultimately a huge cavity developed, the whole of the interior of the nose and the hard palate coming away with the formation of hard crusts. There was also an ulceration of the upper lip, the scars of which are well seen in the photographs. (Figs. 6 and 7.) $\mathrm{He}$ was sent to me as a case of lupus, there being still some discharge from the interior of the nose. The Wassermann reaction was positive. The pabient had two injections of neosalvarsan, which speedily healed up an area of ulceration in the remnant of the nasal cavity.

Mr. F. M. Farmer kindly saw the patient for me with a view to providing some mechanical apparatus which could be made to supply the place of the palate, but this was impossible. A false nose and lip to replace the areas destroyed were the only possible method of improving the patient's condition. This has been provided by Mr. Brook, of Halifax, who had helped us in similar cases.

The points I wish specially to bring out in these cases are: (1) The patients are from 8 to 15 years of age. (2) A history of injury is common. (3) The rapidity of the destruction is quite unlike that met with in lupus vulgaris. Syphilis produced destruction in a few weeks which the tuberculous process takes years to accomplish. (4) The destruction of bone. I have seen many cases of lupus, but lupus does not destroy bone. It eats away cartilage but it does not cause necrosis of bone. The fact that the patient has noticed the presence of dead bone in the discharge from a nasal or palate ulceration is valuable evidence in favour of syphilis. Lastly, I would comment upon the remarkable response of these destructive lesions to antisyphilitic treatment, whether salvarsan, neosalvarsan, or mercury. In any case of doubt I would urge you, in view of the rapidity of the destruction, not even to wait for the Wasserman reaction, but to start antisyphilitic treatment at once. You will do no harm if the patient is tuberculous; you may do irreparable harm by waiting even for a few days if it is syphilitic.

\section{GLYCOSURIA IN THE COURSE OF AFFECTIONS OF THE LIVER: HEPATIC DIABETES.}

BY MARCEL LABBÉ,

PROFESSEUR AgRÉgé at THE UNIVFRSTTY OF PARIS, PHYSIClaN TO LA CHARITÉ;

$$
\text { AND }
$$

AMBROISE BOUCHAGE, M.D. PARIS.

Since Claude Bernard's well-known experiments no one doubts that the liver plays an essential rôle in glycogenesis. Claude Bernard went so far as to say that the cause of diabetes was to be localised in the liver. After him many writers have said that the cause of diabetes, or at any rate of a certain class, was due to hepatic disorders. Lécorché held the opinion that this affection was due to an exaggeration of the hepatic functions. Seegen, Pavy, and Schiff admitted the existence of a hepatogenous diabetes. Glénard has laid great stress upon the lesions found in the liver in diabetes, and has attributed to them the prominent rôle in the causation of the disease. Lately Gilbert was of the opinion that there were two types of diabetes caused by functional hepatic disorders : one due to hyperhepaty, the other to hypohepaty. However, some writers, having frequently found the liver 
untouched in diabetics, do not attribute to it such a preponderant rôle in the causation of diabetes. This being so, we thought it would be of some interest again to raise the question from a clinical point of view and try to determine the relations between hepatic disorders and diabetes.

We will consider the question under fire headings: 1. The glycosurias that occur during the course of hepatic lesions. 2. The hepatic congestions in orerfed people. 3. The post-infectious or toxic hepatic disorders. 4. The "diabète sans dénutrition" with enlarged liver of the overfed. 5. The hepato-pancreatic cirrhosis with severe diabetes.

1. Glycosurias accompanying hepatic lesions.-In cirrhosis and other lesions of the liver (cancer, cardiac liver) the glyco-regulator function is generally disturbed, but not sufficiently to cause what may be called diabetes. Most frequently the alimentary glycosuria test has to be resorted to in order to show the existing glyco-regulator trouble. Sometimes, in more advanced troubles, glycosuria is spontaneous, but intermittent, moderate in amount, and unaccompanied by other symptoms of hyperglycæmia. This form of glycosuria is more often seen at the beginning of cirrhosis of the liver than at a later stage. Sereral of our cases demonstrate the fact.

2. Hepatic congestions. in the overfed.-People indulging in overfeeding, especially with meat, sometimes develop a glycosuria accompanied by hepatic congestion and disturbances in the functions of the liver. This type may be illustrated by the following cases.

CASE 1.-The patient, 29 years of age, had been losing flesh and strength for a year; he was suffering from lumbar pains, and he sought medical advice because he was afraid of phthisis. His complexion was subicteric, the tongue was dirty, and the stomach was dilated. He passed two soft motions a day. The liver was enlarged, measuring 14 centimetres in the mammary line; other organs sound. The urine was scanty ( 1 litre) and contained a large amount of

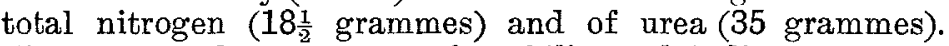
There was a large excess of urobilin and indican present, and some traces of biliary pigments. Six grammes of glucose were found. The patient confessed that he ate too much meat. This was to be suspected from the analysis of his urine. He was placed on a lactovegetarian diet and on a Vichy water cure. In July he felt better. He passed 3 litres of urine per day, containing 7.8 grammes of total nitrogen, 15 grammes of urea, and small quantities of urobilin and indican. The glycosuria ceased; the liver was not so big and measured only 12 centimetres. During September the improvement was maintained. He had put on 2 kilogrammes in weight and there was no glycosuria. In December he was better. The weight had increased by 5 kilogrammes. The liver was smaller and measured only 11 centimetres. Later on the conditions were much the same. If the patient indulged in any alimentary excess, the hepatic disorders reappeared, the liver enlarged again, urobilinuria and glycosuria reappeared, and traces of albumin could be detected in the urine. These symptoms disappeared readily with a lactovegetarian diet.

CASE 2.- The patient, 34 years of age, after presenting some signs of tuberculosis in the lungs in 1900, was sent to the South of France for a rest, and there was submitted to a cure of superalimentation. Besides the ordinary diet he used to take every day 12 raw eggs, $700-800$ grammes of raw meat, and to drink two small claret-glassfuls of cod-liver oil. Under the influence of this diet he improved and increased rapidly in weight.

In 1902 a fresh outbreak of tuberculosis forced him to overfeed again, since which he had eaten a good deal of meat At the beginning of 1907 he had symptoms of muco-mem. branous enteritis. There were very severe pains in the upper part of the ascending colon that suggested appendicitis. and the advisability of an operation was considered. The urine was examined and glycosuria was occasionally found. The patient was then seen by one of us. The tongue was coated, there was a bitter taste in the mouth, and the breath was foul. Stomach normal ; liver slightly enlarged. The urine con. tained some reddish-brown biliary pigment. The lesions in the lungs were apparently completely cured. A diagnosis of gastro-enteritis with congestion of the liver caused by overfeeding was made. A mixed light diet caused immediate improvement.

CASE 3.-The patient, 48 years of age, of sedentary occupation, was a heavy eater, and drank a considerable amount. His general health had been good. For some time he had been complaining of a dull sensation of pain in the lumbar region and had had œdema in his ankles. Examination of the urine revealed a slight amount of glycosuria and the existence of a reddish-brown biliary pigment. He was a rather stout man, and looked older than his age. His complexion was subicteric, and some signs of arterial hypertension were found. The liver was enlarged. A reduction in the amount of the diet quickly diminished the glycosuria. Under the influence of a lacto-vegetarian diet, exercise, and a Vichy water cure he lost some weight and felt more supple and fit. The glycosuria had disappeared in five weeks. The liver had resumed the normal size, and the arterial tension had also fallen.

The story was identical in all these cases. A subject indulges in overfeeding, especially with meat. Sooner or later supervenes a congestion of the liver with functional hepatic disturbances and glycosuria. The patient thinks he is diabetic. In these cases the glycosuria is moderate in amount and unaccompanied by the chief symptoms of hyper. glycæmia. It is noteworthy that this glycosuria disappears at the same time as the other hepatic disorders under the influence of a lacto-vegetarian diet and a Vichy water cure-that is to say, under a diet and treatment that give the liver rest and excite the functions of the hepatic cell.

To treat this class of glycosurias with a meat diet and reduction in the amount of the carbohydrates absorbed would be simply a mistake. Far from curing the existing glycosuria, this diet, on the contrary, would increase it.

Such cases should not be called diabetes. Nevertheless, they are on the borderland of the disease, and if the patients had continued to overfeed perhaps some of them would later have become true diabetics.

3. Post-infections or toxic hepatic disorders.After acute infectious diseases a complexus of hepatic disorders accompanied with glycosuria that reminds one of diabetes is sometimes seen.

CASE 1.-The patient, 32 years of age, was suffering from suppurative tonsillitis with fever. At the outset of the symptoms she had epistaxis and vomited bile. In the last stage of the disease slight glycosuria accompanied with a large amount of urobilin, bile pigments, and ammonia was seen. For several days the urine contained reducing substances in large quantity. These symptoms then disappeared.

CASE 2.-The patient, 56 years of age, was asthmatic and dyspeptic. $\mathrm{He}$ ate much sugar. He was suffering from measles. During the course of that disease he lost flesh rapidly, and in the urine 5 grammes of glucose, 10 centi. grammes of albumin, and some urobilin were found. The liver was slightly enlarged and tender on palpation. He was afraid of diabetes, though presenting no other symptom of hyperglycæmia besides the glycosuria. A mild lacto-vegetarian diet caused the glycosuria to disappear.

These facts can be explained as follows. An affection attacks the various functions of the liver, especially the glyco-regulator function. This will cause a glycosuria which as a rule is moderate in amount. There is here a slightly more advanced stage of what is seen in the course of acute infectious diseases in which the alimentary glycosuria 
test usually shows the existence of glyco-regulator trouble.

Between a simple alimentary glycosuria and a post-infectious diabetes a series of transitory stages exist. It will easily be conceived that with a subject otherwise predisposed or already slightly affected a fresh infection will determine a true diabetes. One of us has given some illustrations of this fact.

4. "Diabète sans dénutrition" with an enlarged liver in the overfed.-This "diabète sans dénutrition" supervenes in those who are in the habit of overfeeding themselves, and is often accompanied with an enlarged liver and disturbances in the functions of that organ.

CASE 1.-The patient, 45 years of age, was a very heavy eater and took no exercise. The abdomen was large and fat. He had suffered from pains in the joints, apparently of a gouty nature, and had had renal colic. He had been a diabetic for several years. On an average about 100 grammes of sugar were now found in the urine. From time to time he had an attack of post-prandial biliary diarrhoea. The liver was slightly enlarged. The patient was of subicteric complexion. A diet with reduction of carbohydrates caused a rapid disappearance of the glycosuria and produced a slight loss of weight. At the same time the digestive troubles ceased.

CASE 2.-The patient, 51 years old, lived a sedentary life, ate a great deal, and drank one litre of wine a day. $\mathrm{He}$ was very obese and had weighed as much as 104 kilogrammes, but now he weighed 96 kilogrammes. In 1901 while suffering from furunculosis, he had an attack of glycosuria, passing 69 grammes of sugar a day. He was put on a special régime, and after a month's treatment he quite recovered. Jater, however, the disease again manifested itself, and in spite of a mineral water cure he passed between 5 and 15 grammes of sugar a day. Digestion was slow. The liver was hypertrophied and reached below the costal margin. The urine indicated an overfed condition and contained 44 grammes of urea ; $1 \cdot 10$ grammes of uric acid; 18 grammes of sodium chloride; and traces of albumin. On the diet being diminished the glycosuria and albuminuria quickly disappeared and the patient lost slightly in weight.

CASE 3.-The patient, 49 years old, ate and drank a great deal. He was obese and suffered from diabetes. When 39 years old, on being examined for life insurance, he was found to be passing sugar in the urine. This disappeared rapidly. When 46 years old, on being again examined, the amount of sugar in the urine was found to be 30 grammes a day, and in spite of careful diet the glycosuria persisted and varied between 30 and 60 grammes a day. The patient was obese, easily tired and out of breath, and complained of his mouth being dry. He went to stool twice daily, the motions being soft. The liver was enlarged, the anterior inferior border reaching 5 centimetres below the costal margin. The patient's complexion was subicteric. He suffered from hemorrboids, and the urine contained 41 grammes of glucose, tngether with urobilin and albumin. Being put on a reduced carbohydrate diet, the glycosuria disappeared after four $\mathrm{d}+\mathrm{ys}$. the albumin was reduced to a trace, the patient lost a little weight, and his general condition was much improved. Subsequently the condition remained stationary. The liver was stıll hard and enlarged. The urine contained traces of albumin and urobilin. However, directly he altered or increased his diet a glyeosuria amounting to several grammes made its appearance.

5. Hepato-pancreatic cirrhosis with severe diabetes.-Lastly, there is a group of diabetes connected with hepato-pancreatic cirrhosis. The aiabète bronzé is of this class. Here the glycosuria is severe and accompanied by nitrogenous waste and often by acidosis; the hepatic cirrhosis is well marked; the cirrhosis of the pancreas is revealed by more or less marked signs of pancreatic insufficiency. Hence, in these cases there is a simultaneous evolntion of a severe glycosuria and of a lesion of the liver and pancreas, but it is impossible to decide whether the liver or pancreas plays the first rôle in the pathology of the diabetes.

Such are the facts, and they show that in the course of hepatic affections one may observe every degree of glyco-regulator disturbance-from the simple alimentary glycosuria induced by the Colrat's test to the most characterised diabetes.

The boundary between diabetic glycosuria and non-diabetic glycosuria is difficult to determine. A hardly appreciable transition leads from one to the other. Arhard and Weil have shown that a certain class of arthritic people who have later on become diabetics began by presenting an alimentary glycosuria. Reciprocally, we have seen true diabetics who, after presenting the complete hyperglycæmic syndrome, when put on a well-regulated diet have only had a very small amount of glycosuria, and finally no glycosuria at all, except when it has been induced by an injection of glucose.

Is there any necessity to group some of those facts under the name of hepatic diabetes? By all means, for it is always possible to argue about that interpretation, since glycosuria is a sign of both hepatic insufficiency and pancreatic, thyroid gland, or nervous insufficiency. Besides, it seems very difficult indeed to say that of all the organs of the glyco-regulator system the liver is the only one attacked. However, it appears to us that the name of hepatic diabetes should be reserved for a certain class of cases in which the alteration of the liver is manifest.

This hepatic diabetes superrenes, as a rule, in heary eaters. It is preceded often by obesity, sometimes by gout or renal lithiasis. It is a mild diabetes without any nitrogenous waste, corresponding to the classical type of the diabete gras or arthritique. It is accompanied by the usual manifestations of alteration of the liver: hyper. trophy of the organ, subicteric complexion, and the presence in the urine of excess of biliary pigments, of brownish-red pigment, of urobilin, ammonia, and the amino-acids. The nitrogen index is low. Again, the patients may sometimes have hæmorrhages and disturbances due to blood coagulation.

The cause of this hepatic diabetes may be a general infection that attacks the liver, an intoxication such as by alcohol, which has an affinity for the liver cells. More often, according to our observations, it is due to overfeeding, especially on meat.

The glyco-regulator disturbance, as a rule benign, may be cured if the anatomical and functional integrity of the liver can be restored. This will show how important is the treatment of hepatic diabetes.

The treatment is chiefly directed to the liver, the basis being mineral water cure such as by the waters of Vichy, Brides, Carlsbad; hepatic opotherapy; lacto-vegetarian régime. While avoiding excess of carbohydrates, it is important to reduce the quantity of meat ingested, the chief cause of the trouble.

Major R. J. Blackham, R.A.M.C., honorary surgeon to the Viceroy of India, who is the Assistant Commissioner of the St. John Ambulance Brigade in India, was the recipient recently of an address of congratulation from the Bombay Corps of the brigade on his being created O.I.E. by the King. The address was enclosed in a beautiful and valuable silver casket. 